\title{
A EDUCAÇÃO AMBIENTAL E OS AGENTES RECICLADORES DA COOPERATIVA RENASCER - CANOAS/RS/BRASIL
}

\author{
Adriana Dias Siemionko ${ }^{1}$, Vanessa Hernandez Caporlingua ${ }^{2}$
}

\begin{abstract}
RESUMO
O artigo busca apresentar a possibilidade da Educação Ambiental contribuir com a emancipação de agentes recicladores da Cooperativa Renascer do município de Canoas/RS/Brasil porque, na sua maioria, são pessoas com baixa escolaridade e com perfil de exclusão social, o que gera dificuldades de inserção no mercado e acesso às políticas públicas. Para tanto, são abordadas reflexões envolvendo a Educação Ambiental crítica, transformadora e emancipatória num projeto de ação realizado no Curso de Especialização em Educação Ambiental da Universidade Federal do Rio Grande - FURG/RS/Brasil. A abordagem metodológica qualitativa, utilizada no projeto, teve como base a coleta de dados através da pesquisa-ação-participante e os resultados apontaram para possíveis transformações individuais e coletivas, obtidas através de atividades de Educação Ambiental promovidas com a intenção de preparar os cidadãos para exigirem justiça social.
\end{abstract}

Palavras Chaves: Agentes Recicladores. Cidadania. Educação Ambiental. Justiça Social.

\section{ABSTRACT}

The article present the possibility of environmental education contribute to the emancipation of recycling agents of the Cooperativa Renascer in the city of Canoas/RS/Brazil, because, sometimes, people with low education and social exclusion profile have difficult for insertion in the work market and access to public policies. Therefore, reflections involving environmental education critical, transformative and emancipatory are addressed in a action project carried out in the Specialization Course in Environmental Education of the Universidade Federal do Rio Grande - FURG/RS/Brazil. The qualitative methodological approach used in the project, was based on data collection through action research participant and the results pointed to possible individual and collective transformations obtained through environmental education activities promoted with the intention to prepare citizens for demand social justice.

Key Words: Recyclers agents. Citizenship. Environmental education. Social justice.

\section{INTRODUÇÃO}

1Graduada em Administração pela UFRGS; Pós-graduada em Gestão Pública pela UFSM; Especialista em Educação Ambiental pela FURG. adsiemionko@gmail.com.

2Doutora em Educação Ambiental; Professora da Faculdade de Direito e do Programa de Pós-Graduação em Educação Ambiental - FURG; líder do grupo de pesquisa Direito e Educação Ambiental GPDEA/CNPQ; vanessac@ vetorial.net. 
A Educação Ambiental (EA) vem sendo incorporada nas mais diversas áreas do conhecimento como uma prática inovadora de caráter interdisciplinar ${ }^{3}$ e transversal. Notadamente, isso acontece porque a perspectiva crítica da EA inclui e enlaça a dimensão social na questão ambiental, ou seja, permite um posicionamento político frente aos dilemas sofridos na atualidade. Tal EA crítica possui potencial emancipatório, pois é matriz de elementos de transformação social inspirados no diálogo, no exercício da cidadania, no fortalecimento dos sujeitos, na compreensão do mundo em sua complexidade e da vida em sua totalidade. Desta forma, as ações vinculadas ao fazer educativo implicam em mudanças individuais e coletivas.

No Brasil, a ação da EA permeia a organização social e assim desempenha importante papel tanto no campo cultural - formando os atores sociais para a gestação de uma ética ecológica, como no campo social - propiciando mudanças rumo ao empoderamento dos indivíduos, grupos e sociedades que se encontram em condições de vulnerabilidade ou desvantagens frente aos desafios da contemporaneidade (BRASIL, 2005).

No entanto, atualmente, as causas das agressões ao meio ambiente ${ }^{4}$ são de diversas ordens, tais como a política, a econômica e a cultural; muitas delas ocorrem devido ao aumento desenfreado dos resíduos sólidos urbanos e principalmente, pela introdução no mercado de produtos descartáveis, ou seja, de produtos utilizados por pouco tempo ou apenas uma única vez para depois serem descartados na natureza.

Embora existam tentativas de atribuir valor econômico aos resíduos para reciclagem, esse tipo de ação não tem levado a uma mudança de estilo de vida e de redução do consumo, mas propiciado o surgimento de uma categoria de trabalhadores, muitas vezes, originária de postos de trabalho extintos e com pouca escolaridade: os agentes recicladores ou catadores de material reciclável. Tais cidadãos são trabalhadores urbanos que coletam, transportam, separam e vendem os resíduos sólidos urbanos recicláveis, tais como papelão, alumínio, vidro e outros.

\footnotetext{
${ }^{3}$ Para Sauvé (1994), a interdisciplinaridade pode estabelecer-se fora dos muros acadêmicos e dos espaços formais da educação e ser dividida em: Cientifica - para a resolução de problemas cognitivos ou para a produção de conhecimentos; Decisiva - para a tomada de decisões na resolução de problemas; Criativa para a produção de um novo objeto - técnico, material ou instrumental; Pedagógica - para favorecer e integração das aprendizagens e das disciplinas.

${ }^{4}$ Entende-se por meio ambiente a relação entre ser humano, natureza e sociedade (CAPORLINGUA, 2012).
} 
Assim, este artigo pretende refletir e descrever ações de EA realizadas com os agentes recicladores de uma cooperativa a partir do desenvolvimento de um projeto realizado no Curso de Especialização em Educação Ambiental da Universidade Federal do Rio Grande - FURG/RS. Para tanto, são relacionados aspectos da EA crítica, transformadora e emancipatória - tomadas como parte dos processos de transformação da sociedade - e os levantamentos de interações prévias com os agentes recicladores da Cooperativa Renascer, localizada no município de Canoas - RS. As referidas ações tiveram por objetivo estimular os agentes à tomada de consciência da realidade, na qual, e com a qual estão inseridos, para possibilitar-lhes delimitar suas ações como atores sociais mais conscientes e atuantes na sociedade.

\section{O CENÁRIO PARA PENSAR EDUCAÇÃO AMBIENTAL}

$\mathrm{Na}$ atualidade, as políticas públicas socioambientais passaram a colocar no eixo da reciclagem os agentes recicladores ou catadores, que vivem a margem social. A $\mathrm{PNRS}^{5}$, em seu artigo $8^{\circ}$, inciso VII e VIII, nomeia a pesquisa científica, assim como a EA, como alguns dos instrumentos necessários para o alcance dos seus objetivos, dentre eles: o desenvolvimento de estratégias sustentáveis; minimização da geração de resíduos e desperdício de materiais; a redução de danos ambientais, além do estímulo a produção/consumo de produtos derivados de materiais reciclados e recicláveis. Já a $\mathrm{PNEA}^{6}$, artigo $1^{\circ}$, conceitua a EA como processo por meio do qual o indivíduo e a coletividade constroem valores sociais, conhecimentos, habilidades, atitudes e competências voltadas para a conservação do meio ambiente, bem de uso comum do povo, essencial à sadia qualidade de vida e sua sustentabilidade.

Dessa forma, existe uma correlação entre as políticas, pois a PNRS é um instrumento fundamental de responsabilidade pública nesta área, exige conhecimentos, posturas, aprendizados e práticas para que as soluções se estabeleçam e desenvolvam mecanismos que promovam a preservação ambiental, a inclusão social, o desenvolvimento sustentado e a colaboração comunitária. A PNEA estabelece a EA como um de seus instrumentos, reforçando a importância desta disciplina e suas metodologias na elaboração dos planejamentos relacionados aos resíduos sólidos.

\footnotetext{
${ }^{5}$ Política Nacional de Resíduos Sólidos Lei no 12.305/2010.

${ }^{6}$ Política Nacional de Educação Ambiental Lei no 9.795, de 27 de abril de 1999.
} 
Assim, a EA constitui-se uma ferramenta com capacidade para construir esses processos.

As práticas de descarte inadequado provocam sérias e danosas consequências à saúde pública e ao meio ambiente. Emoldurando um triste quadro socioeconômico de famílias que, excluídas socialmente, sobrevivem dos denominados lixões de onde retiram os materiais recicláveis que comercializam. Cabe esclarecer que resíduo sólido ou lixo é todo material descartado por não possuir utilidade para quem o descartou e que precisa ser removido em qualquer recipiente destinado a este ato (MONTEIRO et al, 2001).

Desse modo, reduzir, reutilizar e reciclar o que é chamado de lixo (Resíduos Sólidos Urbanos-RSU) se torna uma responsabilidade que a sociedade não tem como se eximir eis que totalmente imbricada na complexidade das relações oriundas do meio ambiente. A geração de RSU apresentou aceleração a partir do advento da Revolução Industrial - segunda metade do século XIX - por fatores ligados ao crescimento e migrações das populações, e aos modelos econômicos adotados (GODECKE et al., 2012).

Imagem da localização da cidade

Fonte: www.sinpro-rs.org.br

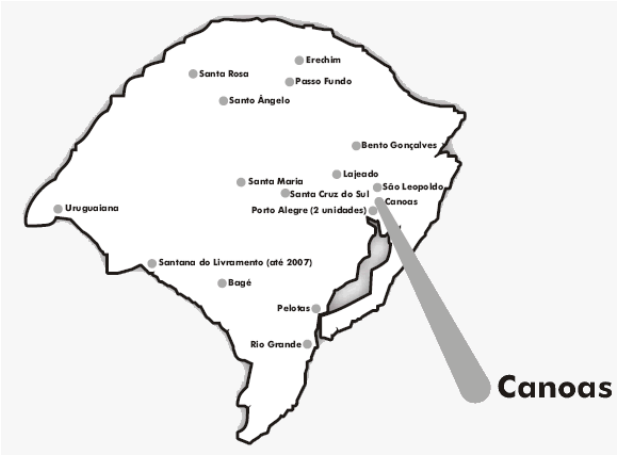

O município de Canoas, onde está inserida a Cooperativa Renascer, está situado no estado do Rio Grande do Sul (RS), mais especificamente na região metropolitana de Porto Alegre, constituída por 31 Municípios. Possui uma população de 323.827 habitantes com uma área de $131 \mathrm{~km}^{2}$; a densidade demográfica (hab./km²) é de 2.470.15.

A população no município de Canoas, entre os anos de 2000 e 2010, aumentou em 5,86\%, enquanto a produção total de resíduos sólidos (domiciliares urbanos e terceiros mais coleta seletiva) teve um acréscimo de $33 \%$, ou seja, uma diferença de 27,14\% a mais que o crescimento demográfico (IBGE, 2010).

Segundo a Lei Municipal de Canoas $\mathrm{n}^{\circ}$ 5451, de 4 de dezembro de 2009, é obrigatória a separação pelos seus produtores do resíduo seco e do resíduo orgânico em 
todo o município. Já o Decreto Municipal $n^{\circ}$ 016/1991 ${ }^{7}$ estabelece que o município deve adotar a reciclagem de resíduos sólidos urbanos, porém não estipula a forma e as condições em que se dará este processo em sua fase final, ou seja, no momento de triagem e destinação dos materiais recicláveis (CANOAS, 1991).

No que se refere ao agente executor da atividade de coleta seletiva, antes mesmo da instituição da PNRS em 2010, a Prefeitura Municipal de Canoas foi pioneira, sendo a primeira do Brasil, na contratação de quatro instituições de reciclagem (cooperativas de catadores). Assim, as cooperativas, por concessão da Prefeitura Municipal, passaram a ser remuneradas para atuar na coleta, transporte e reciclagem dos resíduos sólidos urbanos gerados na área do município, com áreas de atuação delimitadas por zoneamento na forma de quadrantes (Nordeste, Noroeste, Sudoeste, Sudeste). Embora, ainda haja a presença de outras cooperativas e associações sem parceria da prefeitura.

Em 2009 a arrecadação de material reciclado foi de 2.057 ton. e em 2010, foi de 2.514 ton., segundo dados da Prefeitura Municipal de Canoas (CANOAS, 2011). Atualmente, são coletados, aproximadamente, 240 ton. por mês e, em média, cerca de 50 ton. de material reciclado são destinadas para cada cooperativa contratada (CANOAS, 2015).

Para Loureiro (2003) comete-se um erro pedagógico elementar ao predefinirem como prioridade absoluta um problema que não é entendido desse modo por todos homogeneamente. Afinal, se resíduos sólidos urbanos são uma questão urgente da vida urbana em termos macro, sua gravidade deve ser entendida na especificidade de cada localidade e particularidade. Assim, os resíduos jogados fora podem ser transformados e transformar a vida das pessoas.

Em Canoas, a catação iniciou com um grupo de trabalhadores informais atuando no antigo lixão da cidade, onde hoje fica o aterro sanitário (desativado em 12/2010). No ano de 2001, esse grupo formou a primeira associação e, em 2011, criaram a cooperativa e a batizaram de Renascer. Portanto, a Cooperativa Renascer se originou do primeiro grupo de reciclagem de Canoas, que está em atividade desde 1976.

\section{A EDUCAÇÃO AMBIENTAL CRÍTICA, TRANSFORMADORA E EMANCIPATÓRIA}

\footnotetext{
${ }^{7}$ Regulamenta a Lei no 3.007 de 31 de outubro de 1990.
} 
A EA é educação, e o seu maior objetivo é produzir conhecimentos sobre os processos educativos em que se envolve. Assim, por meio das reflexões de Loureiro (2003) é possível entender que EA permite abordar os aspectos socioambientais das relações humanas, participação e transformação da realidade de vida, voltada para o exercício da cidadania na problematização e transformação das condições de vida e na ressignificação de nossa inserção no ambiente.

Pensar uma EA crítica, transformadora e emancipatória com trabalhadores que desenvolvem suas atividades em cooperativas de reciclagem de resíduos é definir que a crítica acontece na medida em que se discute e se explicita a relação ser humano, sociedade e natureza e as interações relacionais daí instituídas. Transformadora, pois acredita na capacidade da humanidade construir outro futuro a partir do passado com vistas no presente e, assim, instituindo relações dos seres humanos entre si, com a sociedade e com a natureza. Portanto, se torna também emancipatória, por tomar a liberdade como valor fundamental e buscar a produção da autonomia dos grupos oprimidos e excluídos (QUINTAS, 2004).

Importante compreender a EA num contexto mais amplo no sentido de uma educação para a cidadania, configurando-a como elemento determinante para a consolidação de sujeitos cidadãos. A cidadania diz respeito à identidade e ao pertencimento a uma coletividade, assim, a EA como formação e exercício de cidadania se refere a uma nova forma de encarar a relação do ser humano, com a sociedade e com a natureza, baseada numa nova ética, que pressupõe outros valores morais e uma forma diferente de ver e intervir no mundo (JACOBI, 2003).

Quando se trata de uma EA voltada para a cidadania se percebe o quanto a EA é política, e conforme afirma Reigota (2009), a EA é uma forma de educação política em que o indivíduo participa ativamente reivindicando e exigindo melhorias no âmbito social, político e econômico. Logo, tal educação deve estar orientada para a sociedade, com indivíduos participando ativamente da resolução dos problemas e das questões socioambientais.

Tais questões para ser objeto de outras formas de agir e de transformar necessitam do desvelamento de um saber social e um saber ambiental entrelaçados, pois o saber social emerge do encontro de seres diferenciados pela diversidade cultural e o saber ambiental produz novas significações sociais, o que implica na apropriação de conhecimentos e saberes dentro de distintas racionalidades culturais e identidades 
étnicas (LEFF, 2009). Destaca-se que, a partir da conjugação entre saber social e saber ambiental, foi realizado o projeto de ação de EA.

No mesmo sentido fundamenta o documento governamental ProNEA ${ }^{8}$, no qual os pressupostos da EA crítica e emancipatória passam pelas transformações simultâneas das condições individuais e coletivas, objetivas e subjetivas, materiais e simbólicas, transformações essas que ocorrem tendo em vista a identificação de grupos sociais marginalizados e vulneráveis diante das zonas de conflito estabelecidas pelos efeitos do capitalismo desenfreado:

Há um último elemento norteador do documento governamental federal que queremos destacar: o reconhecimento de que a definição dos sujeitos do processo educativo passa pela identificação dos grupos sociais em condições de vulnerabilidade ambiental, decorrentes dos riscos a que estão submetidos em função de preconceitos e/ou desigualdade econômica na sociedade. Evitase, deste modo, a perigosa generalização "pensar a humanidade" sem considerar o contexto que permite entender as diferentes relações sociais na natureza. Mesmo sendo um conceito trabalhado no campo das ciências sociais, e com destaque pelo internacionalmente denominado movimento de justiça ambiental, vulnerabilidade ambiental é termo ainda pouco presente em educação ambiental, resultando em práticas que ignoram a dinâmica societária na qual estamos imersos (LOUREIRO, AZAZIEL \& FRANCA, 2003 apud LOUREIRO, 2004b) - grifos no original.

Portanto e segundo Loureiro (2004), a EA transformadora possui um conteúdo emancipatório, a partir de uma matriz que vê na educação um elemento de transformação social, em que as atividades humanas relacionadas ao fazer educativo provocam transformações individuais e coletivas, locais e globais, bem como econômicas e culturais. Desse modo, a tendência crítica, transformadora e emancipatória se caracteriza por possuir atitude problematizadora e reflexiva diante dos desafios que a crise civilizatória apresenta, partindo assim do princípio de que o modo de vida atual não atende mais aos anseios e a compreensão de mundo de que é preciso para criar outros caminhos.

São os eixos explicativos da EA transformadora que, segundo Loureiro (2004a), dão suporte para: redefinir o modo como o ser humano se relaciona consigo, com as demais espécies e com o planeta; estabelecer a participação e o exercício da cidadania como princípios para a definição da democracia e de relações mais adequadas com

\footnotetext{
${ }^{8}$ ProNEA - PROGRAMA NACIONAL DE EDUCAÇÃO AMBIENTAL: Programa iniciado em 1996 pelo governo federal e que tem por objetivo promover a Educação Ambiental em todos os níveis de ensino e a conscientização pública para garantir o ambiente ecologicamente equilibrado.
} 
relação à vida planetária; educar para transformar e romper com as práticas sociais contrárias ao bem-estar público, à equidade e à solidariedade, estando articulada necessariamente às mudanças éticas que se fazem pertinentes.

Além disso, é preciso promover a democracia como condição para a construção de uma sustentabilidade substantiva e disseminar a convicção de que o exercício da participação social e o exercício pleno da cidadania são práticas indispensáveis a tal democracia e à emancipação socioambiental. Desse modo, o grande desafio que se apresenta é a busca por mudanças e transformação dos valores e práticas socioambientais contrárias ao bem-estar público e à equidade.

Promover a EA é querer um mundo diferente, com a fruição dos direitos fundamentais para todos os cidadãos indistintamente. É buscar ações de transformação para uma vida melhor no presente e no futuro. É olhar para a relação ser humano, sociedade, natureza com os olhos do coração e respeitar todos os seres da inter-relação e interdependência dos elementos presentes no meio ambiente.

\section{A PRÁXIS EDUCATIVA 9}

A EA crítica, transformadora e emancipatória, especificamente no contexto da gestão dos resíduos, é aquela que contribui para o processo de fortalecimento da autoestima e o despertar do interesse por si próprio — autovalorização — através da percepção acerca da saúde, da segurança no trabalho e do trabalho cooperativado; a promoção da noção de pertencimento como indivíduo e grupo social; e o reconhecimento das capacidades individuais e coletivas para a busca da autossuficiência para além da triagem de resíduos. Logo, foi base para a proposta de um projeto de ação de Educação Ambiental com tais intencionalidades.

Foi no ano de 2012 que se realizou uma pesquisa, por meio de entrevista com os trabalhadores da reciclagem, a fim de obter uma abordagem sobre a questão socioambiental dos resíduos. Tal pesquisa de campo subsidiou o desenvolvimento do

\footnotetext{
${ }^{9}$ A palavra tem origem grega e a expressão práxis refere-se, em geral, a ação, a atividade prática. Karl Marx, concebe a práxis, no sentido de atividade livre, universal, criativa e auto criativa, por meio da qual o homem cria (faz, produz), e transforma (conforma) seu mundo humano e histórico e a si mesmo; atividade específica ao homem, que o torna basicamente diferente de todos os outros seres. Práxis é a reflexão e ação dos homens sobre o mundo para transformá-lo (BOTTOMORE, 2012).
} 
Trabalho de Conclusão de Curso de Especialização em Gestão Pública, da Universidade Federal de Santa Maria - UFSM (SIEMIONKO, 2012) ${ }^{10}$.

A Cooperativa de Reciclagem de Lixo Amigas Solidárias - Cooarlas, fundada em outubro de 1999, sediou tal pesquisa de campo e proporcionou observações que muito contribuíram para o estudo. Em 2012, a cooperativa possuía cerca de 30 associados cuja grande maioria era composta por mulheres, com baixa escolaridade e mães de família. Alguns desses cooperados não quiseram dar entrevista e seu desejo foi respeitado, portanto, foram realizadas 15 entrevistas diretas com os cooperados, além de conversas com seus líderes e uma longa conversa informal, com uma das seis fundadoras. As descobertas despertaram inquietações sobre a qualidade de vida e de trabalho dessas pessoas, e que resultaram no problema motivador do projeto de ação em EA desenvolvido no curso de Especialização em Educação Ambiental da FURG.

O referido Projeto de EA, desenvolvido na Cooperativa Renascer, na cidade de Canoas/RS, buscou investigar se através da EA crítica, transformadora e emancipatória é possível melhorar a realidade dos agentes recicladores de resíduos sólidos urbanos.

O projeto de ação utilizou a abordagem qualitativa, modalidade descritiva e o enfoque metodológico da pesquisa-ação-participante, para alcançar os objetivos estabelecidos. A escolha metodológica se deu porque a pesquisa participante é aquela em que o pesquisador, para realizar a observação dos fenômenos, compartilha a vivência dos sujeitos pesquisados observando as manifestações dos sujeitos e as situações vividas, vai registrando descritivamente todos os elementos observados, bem como as análises e considerações que fizer ao longo dessa participação.

Permite, além de compreender, intervir na situação, com vistas a modificá-la, pois o conhecimento se articula a uma finalidade intencional de alteração da situação pesquisada. Assim, ao mesmo tempo em que realiza um diagnóstico e a análise de uma determinada situação, a pesquisa-ação propõe ao conjunto de sujeitos envolvidos mudanças que levem a um aprimoramento das práticas analisadas (SEVERINO, 2007).

Também Brandão (2005), sustenta no mesmo sentido que se deve partir da realidade concreta da vida cotidiana dos próprios participantes individuais e coletivos do processo em suas diferentes dimensões e interações. Já Tozoni-Reis (2007) pontua a

\footnotetext{
${ }^{10}$ Intitulado Catadores De Resíduos Sólidos Urbanos Em Canoas/RS: Um Estudo Dos Aspectos Sociais, Econômicos e Ambientais.
} 
pesquisa-ação-participante como adequada para educadores ambientais, pois evita o distanciamento entre teoria e prática e se obtém resultados a curto-prazo.

Os instrumentos de coleta de dados utilizados no levantamento das informações foram: pesquisa bibliográfica e documental, participação em ciclos de palestras e seminários sobre o tema da pesquisa, além das entrevistas com os trabalhadores da reciclagem.

A pesquisa bibliográfica foi realizada a fim de dar suporte ao aprendizado necessário à realização da pesquisa, bem como para buscar o estado da arte. Já a pesquisa documental foi feita por ser importante "técnica de identificação, levantamento, exploração de documentos fontes do objeto pesquisado e registro de informações". O uso das entrevistas ocorreu com o objetivo de colher "informações dos sujeitos a partir do seu discurso livre” e, através de um diálogo descontraído, obter a impressão do entrevistado sobre o assunto (SEVERINO, 2007, p. 124).

Assim, realizou-se uma visita à Cooperativa Renascer para apresentar a proposta do projeto e conhecer os cooperados, quando ficaram combinadas as próximas visitas semanais.

$\mathrm{Na}$ segunda visita foi feita uma entrevista guiada junto aos vinte e seis trabalhadores da reciclagem da cooperativa, a qual foi feita com o objetivo de compreender dos entrevistados suas experiências, perspectivas, alternativas, condicionamentos e suas percepções em relação à atividade laboral que desempenham atualmente. Em grande parte, tornou-se uma conversa informal, onde eram relatadas experiências e vivências do cotidiano na cooperativa. As informações obtidas serviram de subsídios para compor o foco de ação do projeto em EA, pois a entrevista investigou as dimensões social, econômica e ambiental dos cooperados: 


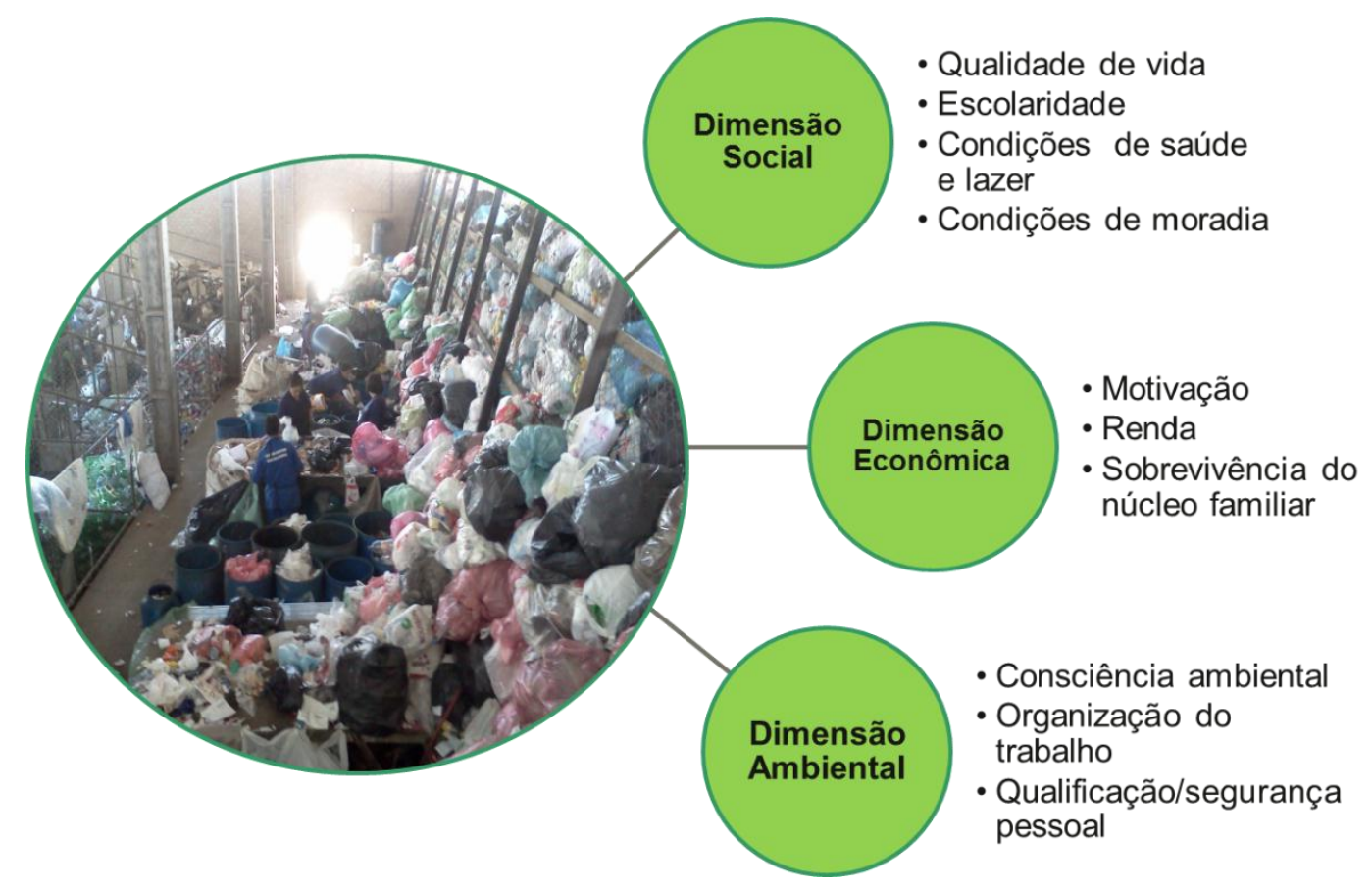

No terceiro encontro foi realizado um minicurso para todos os cooperados, quando se apresentaram os princípios do cooperativismo, as noções sobre saúde e segurança do trabalho, ressaltando a importância e os cuidados necessários com as mãos, já que elas são a principal ferramenta de trabalho; e as noções sobre cooperação e trabalho em equipe. No final do encontro foi apresentado vídeo motivacional sobre superação buscando ressaltar a autoestima individual como forma de mostrar-lhes a capacidade de transformar a realidade em que estão inseridos. Neste momento houve uma maior interação, o que possibilitou a percepção de que o trabalho realizado de alguma forma os deixou diferentes frente à situação cotidiana. Principalmente, em relação à segurança e o uso de equipamentos de proteção, pois muitos não tinham o conhecimento sobre a importância da proteção individual, especialmente, as mãos. Aqui foi possível identificar transformações individuais e coletivas, descritas por Loureiro (2003), uma vez que o conteúdo emancipatório inserido naquele fazer educativo os fez perceber as responsabilidades com o próprio corpo e com os colegas frente à atividade laborativa diária.

No último encontro, foi realizada outra entrevista com os trabalhadores para poder avaliar e perceber se o trabalho desenvolvido de alguma forma mudou a maneira deles encararem o mundo e se posicionarem frente às diversas adversidades que encontram na sua jornada. 


\section{AS DESCOBERTAS COM A EDUCAÇÃO AMBIENTAL EMANCIPATÓRIA}

As descobertas da pesquisa foram no sentido de tentar promover a inclusão social dos agentes recicladores por meio de políticas públicas socioambientais. $\mathrm{Na}$ atualidade, estas políticas passaram a colocar no eixo da reciclagem os respectivos trabalhadores, que vivem à margem social.

A dimensão social evidenciou que a maioria dos trabalhadores são mulheres, com três ou mais filhos e com baixa escolaridade ou analfabetos. Dentre homens e mulheres, cerca de $80 \%$ não procuram o dentista regularmente. Metade do público feminino não costuma realizar exames de prevenção de câncer de mama e colo do útero. Com relação à utilização de método anticoncepcional, entre homens e mulheres, em torno de $60 \%$ diz não usar ou não tomar nenhum cuidado para evitar filhos. Sendo que esses serviços são oferecidos gratuitamente pela rede pública de saúde - SUS ${ }^{11}$, na cidade de Canoas/RS.

Os resultados encontrados na dimensão social demonstraram que ainda há muito trabalho a ser feito para a inclusão desses trabalhadores, pois, segundo Reigota (2009), tal educação deve estar orientada para a comunidade e com indivíduos participando ativamente da resolução dos problemas, reivindicando e exigindo melhorias no âmbito social, político e econômico.

A dimensão econômica, por sua vez, levou a perceber que todos os discursos apontam para que os trabalhadores da reciclagem, quando organizados em cooperativas e associações, podem incrementar a sua renda e a continuidade do negócio é considerada viável. Sabe-se que, embora organizados em cooperativas, a atividade produz uma dificuldade de construção de uma identidade coletiva e profissional, diante de todo o legado de exclusão vivido por essa classe. Faltam-lhes conhecimentos sobre associativismo e cooperativismo, tendo em vista a manutenção da postura de empregados, ou seja, não possuem a consciência de que são autônomos para criar e moldar sua rotina de trabalho.

A dimensão ambiental esclareceu como ocorre a organização do trabalho e se isso causa um impacto não só em suas vidas, mas na de todos da localidade onde exercem suas atividades. Os trabalhadores da reciclagem entrevistados, na maioria, são

\footnotetext{
${ }^{11}$ O Sistema Único de Saúde é um dos maiores sistemas públicos de saúde do mundo. Ele abrange desde o simples atendimento ambulatorial até o transplante de órgãos, garantindo acesso integral, universal e gratuito para toda a população do país.
} 
motivados pelos ganhos financeiros, isto é, utilizam a reciclagem como fonte de renda e sustento da família. Existem também aqueles que declararam gostar da atividade e que se identificam com o ambiente de trabalho. Compreendeu-se que todos estão envolvidos com a questão ambiental e possuem consciência do exercício da cidadania ambiental e da importância do seu trabalho para a preservação do meio ambiente.

Nesse sentido, Jacobi (2003) evidencia a cidadania como elemento determinante para a consolidação de sujeitos cidadãos. Para ele cidadania tem a ver com a identidade e o pertencimento a uma coletividade. Esse ponto está presente dentro da cooperativa trabalhada, embora, perceba-se a ausência de outros aspectos também importantes na vida dos agentes ambientais cidadãos.

Descobriu-se também sobre o risco de contaminação e a falta de Educação Ambiental da população, pois a cooperativa, que sediou a pesquisa, recebe não somente resíduo para reciclagem, mas seringas, agulhas, cacos de vidro, fezes e resíduo orgânico, os quais se encontram nos galpões de triagem. Assim, parte-se da premissa que todo dano ambiental vem associado a um dano social.

Neste ponto, percebe-se o distanciamento da sociedade local em relação a EA e a legislação vigente, pois, ainda dentro da regulamentação da PNRS, o artigo 77 do Decreto $\mathrm{n}^{\circ} 7.405$ estabelece que:

[...] a educação ambiental na gestão dos resíduos sólidos é parte integrante da Política Nacional de Resíduos Sólidos e tem como objetivo o aprimoramento do conhecimento, dos valores, dos comportamentos e do estilo de vida relacionados com a gestão e o gerenciamento ambientalmente adequado dos resíduos sólidos.

Partindo das compreensões analisadas nas quatro dimensões investigadas, bem como levando em consideração as interações ocorridas entre elas, chega-se a insustentabilidade das relações totalmente esgotadas pela marginalização preconizada por um sistema de mundo comprovadamente falido e propulsor de danos ao meio ambiente e das próprias relações de sentido provenientes da exclusão e do poder de gerar conflitos controladores.

A EA emancipatória passa a ser fim e ao mesmo tempo objetivo perseguido para a mudança de paradigma civilizatório em que o saber ambiental não é mais relevante do que a indolência daqueles que não acreditam na possibilidade de transformação para um mundo melhor.

\section{CONSIDERAÇÕES FINAIS}


O artigo apresentou a dinâmica realizada na Cooperativa Renascer em Canoas/RS para permitir compreender que, através da EA crítica, transformadora e emancipatória, é possível intervir de forma a estabelecer iniciativa pessoal e estimular às pessoas a tomarem consciência da realidade na qual e com a qual estão inseridas, para possibilitar-lhes agir como atores sociais conscientes e atuantes na sociedade.

O cerne da EA crítica é a problematização da realidade e a prática educativa é a formação do sujeito humano enquanto ser individual e social, historicamente situado. Assim, o estudo buscou a práxis em EA como forma de emancipação de minorias excluídas, ofereceu uma compreensão da realidade dos agentes recicladores e sua atuação na sociedade.

As situações conhecidas por meio da pesquisa-ação-participante realizada junto a Cooperativa revelou a falta de informação e consciência para buscar o espaço da cidadania que foi abusivo e ostensivamente sequestrado pela marginalização daqueles considerados objeto e não sujeitos de direitos. Desvelou a necessidade do empoderamento, da empregabilidade, do conhecimento técnico, do comprometimento mútuo e da capacidade de articulação em prol de benefícios comum.

Assim, a realidade dos agentes recicladores acena para a possibilidade da EA crítica, transformadora e emancipatória, com seus preceitos, ajudar a reconstruir atitudes para o enfrentamento da realidade social em que vivem. Tendo em vista que o grande distanciamento existente entre a ação dos agentes recicladores deve ser permeado por outros paradigmas que possam sustentar mudanças para políticas públicas de inclusão e de promoção de justiça social.

Pensar outros paradigmas poder ser reconstruir compreensões a partir de saberes daqueles que enfrentam a marginalização e exclusão do sistema, o qual já serve para promover a injustiça estabelecida não mais na hegemonia dos conceitos, mas na preponderância do poder de controle das relações entre ser humano, natureza e sociedade.

\section{REFERÊNCIAS}

BOTTOMORE, T. Dicionário do Pensamento Marxista. Editado por Editora Zahar. 2012.

BRANDÃO, C. R. Pesquisa Participante In. ENCONTROS E CAMINHOS: FORMAÇÃO DE EDUCADORAS(ES) AMBIENTAIS E COLETIVOS EDUCADORES. MMA, Diretoria de Educação Ambiental, Brasília. 2005. 
BRASIL. Lei $\mathbf{n}^{\mathbf{0}}$ 12.305, de 02 de agosto de 2010. Institui a Política Nacional de Resíduos Sólidos; altera a Lei $\mathrm{n}^{\circ}$ 9.605, de 12 de fevereiro de 1998 e dá outras providências. Disponível em: http://www.planalto.gov.br/ccivil_03/_ato20072010/2010/lei/l12305.htm Acesso em: 26 dez. 2011.

Ministério do Meio Ambiente - MMA. ProNEA- Programa nacional de educação ambiental. Brasília, 2005.

Lei no 9.795, de 27 de abril de 1999. Dispõe sobre a educação ambiental, institui a Política Nacional de Educação Ambiental e dá outras providências. Disponível em: http://www.planalto.gov.br/ccivil_03/leis/19795.htm. Acesso em: 26 jun. 2014.

Constituição (1988). Constituição da República Federativa do Brasil. Brasília, DF: Senado Federal: Centro Gráfico, 1988.

CANOAS (Cidade). Lei $\mathbf{n}^{\mathbf{0}}$ 5451, de 4 de dezembro de 2009. Estabelece a obrigatoriedade na separação do lixo seco e do lixo orgânico em canoas. Revogam-se as leis no 3007 de 31 de Outubro de 1990, 4594 de 28 de novembro de 2001 e 4648 de 20 de junho de 2002, Canoas, RS. 2009.

CAPORLINGUA, V. H. A consciência ambiental dos juízes nas sentenças transformadoras. Jundiaí: Paco Editorial, 2012.

GODECKE, M. V.; CHAVES, I. R.; NAIME, R. H. Gestão de Resíduos Sólidos Urbanos No Brasil: O Caso de Canoas, RS. Rev. Elet. em Gestão, Educação e Tecnologia Ambiental (e-ISSN: 2236-1170). V(7), n 7, p. 1430-1439, Mar-Ago, 2012. Disponível em: http://cascavel.ufsm.br/revistas/ojs-2.2.2/index.php/reget/index. Acesso em: 12 out. 2012.

IBGE - INSTITUTO BRASILEIRO DE GEOGRAFIA E ESTATÍSTICA. Cidades. IBGE, Disponível em: http://www.ibge.gov.br. Acesso em: 03 nov. 2012.

- INSTITUTO BRASILEIRO DE GEOGRAFIA E ESTATÍSTICA. Cidades. IBGE. Disponível em: http://cod.ibge.gov.br/232NV. Acesso em: 15 jun. 2015.

JACOBI, P. Educação ambiental, cidadania e sustentabilidade. Cadernos de Pesquisa, n. 118, p.197. Março/ 2003. Disponível em: http://www.scielo.br/pdf/cp/n118/16834.pdf. Acesso em: 30 jun. 2014.

JORDÃO FILHO, R. S.; OLIVEIRA, T. S. M. Planejamento e Sustentabilidade Urbana. Caderno Organização Sistêmica Uninter. V. 3, n. 2, p. 53-65, 2013. Disponível em:

http://www.grupouninter.com.br/revistaorganizacaosistemica/index.php/cadernoorganiz acaosistemica/article/view/211. Acesso em: 05 ago. 2014.

JORNAL DE CANOAS. Informativo da Prefeitura Municipal de Canoas - Jan de 2011 - Edição XXII - Ano III. p. 7.

LEFF, E. Complexidade, Racionalidade Ambiental e Diálogo de Saberes. Revista Educação e Realidade 34(3): p. 17-24, set/dez 2009.

A Complexidade Ambiental. Tradução e coordenação de Eliete Wolf.

São Paulo: Editora Cortez, 2003.

LOUREIRO, C. F. B. Premissas teóricas para uma educação ambiental transformadora. Revista Ambiente e Educação, Rio Grande, RS, p. 37-54, 2003.

Trajetórias e Fundamentos da Educação Ambiental. São Paulo:

Cortez, 2004.

Educar, participar e transformar em educação ambiental. In: REVISTA BRASILEIRA DE EDUCAÇÃO AMBIENTAL. Rede Brasileira de Educação Ambiental. Número 0, p. 63-70, 2004a, Brasília, DF.

Educação Ambiental Transformadora. In: IDENTIDADES DA EDUCAÇÃO AMBIENTAL BRASILEIRA. Ministério do Meio Ambiente. Diretoria 
de Educação Ambiental; Coordenação de Philippe Pomier Layrargues. Brasília: Ministério do Meio Ambiente, 2004b. 156 p.

HENDGES, A. S. Educação Ambiental e Resíduos Sólidos. Disponível em: http://www.ecodebate.com.br/2012/03/01/educacao-ambiental-e-residuos-solidosporantonio-silvio-hendges/. Acesso em: 23 abr. 2015.

HIGUCHI, M. I. G.; AZEVEDO, G. C. Educação como processo na construção da cidadania ambiental. In: REVISTA BRASILEIRA DE EDUCAÇÃO AMBIENTAL.

Rede Brasileira de Educação Ambiental. Número 0, Pág. 63-70, Nov 2004, Brasília, DF.

MONTEIRO, J. H. P. et al. Manual de Gerenciamento Integrado de Resíduos Sólidos. Rio de Janeiro: IBAM, 2001.

QUINTAS, J. S. Educação no processo de gestão ambiental: uma proposta de educação ambiental transformadora e emancipatória. In: MMA. DEA. Identidades da educação ambiental brasileira. Coordenação de Philippe Pomier Layrargues. p. 113140. Brasília: Ministério do Meio Ambiente, 2004, 156 p.

REIGOTA, M. O que é educação ambiental. $2^{\mathrm{a}}$ ed. Brasiliense: São Paulo, 2009.

SAUVÉ, L. Pour une Éducation Relative à L'Environnement. Montréal: Guérin Éditeur, 1994. apud SATO, M.; PASSOS, L. A.. Notas desafinadas do saber e do poder: qual a rima necessária a educação ambiental. Contrapontos, Itajaí, v. 3, n. 1, p.9-26, mar. $2009 . \quad$ Disponível em: <http://www6.univali.br/seer/index.php/rc/article/view/700/553>. Acesso em: 09 mai. 2015.

SEVERINO, A. J. Metodologia do trabalho científico. 23. ed. São Paulo: Cortez, 2007.

SIEMIONKO, A. D. A Percepção da Incorporação dos Riscos Socioambientais na Análise de Crédito Sob o Olhar do Público Interno do Banco Lisa. Trabalho de Conclusão para obtenção do título de Bacharel em Administração. UFRGS - EA Porto Alegre - 2010. Disponível em: http://hdl.handle.net/10183/29851. Acesso em: 06 out. 2011.

A.D. Catadores De Resíduos Sólidos Urbanos Em Canoas/Rs: Um

Estudo Dos Aspectos Sociais, Econômicos E Ambientais. Monografia de Especialização em Gestão Pública. Centro de Ciências Sociais e Humanas Programa de Pós-Graduação. UFSM, Santa Maria, RS. 2012.

TOZONI-REIS, M. F. C., Org. A pesquisa-ação-participativa em educação ambiental: reflexões teóricas. São Paulo: Annablume, Fapesp, Fundibio, 2007. 